\title{
A relação da escolarização e os efeitos para a escolha do projeto de vida de estudantes surdos
}

\author{
The relationship of education and the effects for the choice of the project of life \\ of deaf students
}

\section{La relación de la educación y los efectos de la elección del proyecto de vida de los estudiantes sordos}

\author{
Arlete Marinho Gonçalves ${ }^{2}$
}

\begin{abstract}
Resumo: O estudo tem como objetivo apreender a relação da escolarização e os efeitos para a escolha do projeto de vida de estudantes Surdos. A fundamentação teórica está embasada na Teoria das Representações Sociais (RS) de abordagem dimensional. Tem-se como metodologia a abordagem descritiva - analítica com a utilização da técnica de associação livre de palavras. Os dados foram analisados a partir da associação entre fatores que se relacionam para se chegar as RS. Os resultados apontam que os projetos de vida dos estudantes Surdos se estruturam a partir da construção histórica de suas vivências no âmbito escolar, principalmente às relacionadas na educação básica. Esse processo ajudou os alunos Surdos a ter conhecimento, enfrentar desafios, se desenvolver e descobrir seus interesses. As correlações que assinalam a escolarização foram apontadas por representações de situações de exclusão, a descoberta da Língua de Sinais como opção para o seu desenvolvimento escolar e a escolha da faculdade.
\end{abstract}

Palavras-chave: Escolarização de Surdos. Projeto de Vida. Representações Sociais.

\begin{abstract}
The study aims to capture the relationship of schooling and the effects for the choice of the project of life of deaf students. The theoretical foundation is based on the theory of social representations (RS) of onedimensional approach. Has as descriptive-analytic approach methodology with the use of the technique of free association of words. Data were analyzed from the association between factors that relate to the RS. The results show that the lives of deaf students are structured from the historical construction of their livings under school, mainly to related in basic education. This process helped the deaf students to have knowledge, face challenges, develop and discover their interests. The correlations that indicate the education were pointed out by representations of situations of exclusion, the discovery of sign language as an option for its development and the choice of College.
\end{abstract}

Keywords: Education of the deaf. Life project. Social representations.

Resumen: El estudio tiene como objetivo captar la relación de la educación y los efectos de la elección del proyecto de vida de los estudiantes sordos. La fundamentación teórica se basa en la teoría de las representaciones sociales (RS) del enfoque unidimensional. Tiene como metodología de enfoque descriptivo analítico con el uso de la técnica de asociación libre de palabras. Se analizaron datos de la asociación entre los factores que se relacionan con la RS. Los resultados muestran que las vidas de los estudiantes sordos se estructuran desde la construcción histórica de sus vivencias en la escuela, principalmente relacionadas con educación básica. Este proceso ayudó a los estudiantes sordos tener conocimiento, enfrentan retos, desarrollar y descubrir a sus intereses. Las correlaciones que indican la educación fueron precisadas por las representaciones de las situaciones de exclusión, el descubrimiento de cómo opción de lengua de signos para el desarrollo de la escuela y la elección de la Universidad.

Palabras clave: Educación de los Sordos. Proyecto de Vida. Representaciones Sociales.

\footnotetext{
${ }^{1}$ Submetido em: 24 set. 2016 - Aceito em: 12 mar. 2019 - Publicado em: 25 mar. 2019.

${ }^{2}$ Universidade Federal do Pará (UFPA) - E-mail: arletmarinho@ gmail.com
} 


\section{Introdução}

É necessário compreender que os sujeitos Surdos, em especial, os sinalizadores, se comunicam de forma viso-espacial, e tem como referência: a configuração das mãos, o ponto de articulação, a orientação, a direção do sinal, e, a expressão facial e corporal, diferentemente dos ouvintes, que se comunicam de forma oral-auditiva e dos deficientes auditivos $^{\mathrm{i}}$ com resíduos auditivos ou não, que direcionam seu olhar exclusivamente para a leitura labial ou para os resíduos sonoros. Essa forma de comunicação, não os impede de viver em sociedade e interagir com outros sujeitos, seja ele Surdo (sinalizador ou oralizado) ou ouvinte.

O Censo Demográfico de 2010 aponta que temos atualmente um total de 9.717.318 Surdos ou deficientes auditivos no Brasil, o que representa $5,1 \%$ da população brasileira. Desses, 2,1 milhões são pessoas com deficiência auditiva severa, 344,2 mil são consideradas surdas e 1,7 milhões tem dificuldades de ouvir. Desse total, 21.628 estão na região norte e o estado do Pará conta com 10.604, dos quais 4.142 não são alfabetizados (BRASIL, 2010).

Os dados revelam que o Estado do Pará apresenta muitas lacunas, no que diz respeito aos direitos legais dos sujeitos Surdos, principalmente, quando se trata da escolarização. Apesar de as políticas sociais e "inclusivas" estarem postas, os dados sobre os alunos Surdos que ainda não são alfabetizados são alarmantes. É necessário investigar o que produz a exclusão desses sujeitos na escola e/ou o porquê de não conseguirem alcançar o ensino superior, e ainda, aos que nem entraram na escola.

Arriscamo-nos a dizer, que, talvez, a falta de escolas preparadas para receber essas crianças, seja uma das causas, e/ou a falta de profissionais qualificados para atender o aluno na sua língua primeira. São questões que merecem a nossa reflexão. A respeito disso, Damázio (2007, p. 14) ressalta que:

\footnotetext{
As pessoas com surdez enfrentam inúmeros entraves para participar da educação escolar, decorrentes da perda da audição e da forma como se estruturam as propostas educacionais das escolas. Muitos alunos com surdez podem ser prejudicados pela falta de estímulos adequados ao seu potencial cognitivo, sócioafetivo, linguístico e político-cultural e ter perdas consideráveis no desenvolvimento da aprendizagem.
}

A autora afirma ainda que a inclusão do aluno com surdez deve acontecer desde a educação infantil até a educação superior, no sentido de garantir, desde cedo, meios para superar as barreiras no processo educacional e, assim, poder usufruir de seus direitos escolares, sua cidadania, preconizado nos princípios constitucionais do nosso país.

Os entraves decorrentes dos processos de escolarização dos Surdos, sem estar num lugar propício para o seu desenvolvimento linguístico natural ou com acessibilidade necessária, pode ser um dos motivos que impulsiona o jovem a não conseguir, na maioria das vezes, entrar na universidade. É nesse contexto, que o universitário Surdo ganha destaque neste estudo, pois para eles, a chegada se dá dentro do tempo e das oportunidades, além das grandes dificuldades de acessibilidade comunicacional e informacional encontrada ao longo do caminho ${ }^{\text {ii }}$. 
A acessibilidade comunicacional necessária seria aquela que proporcionasse um ambiente propício linguisticamente para os alunos Surdos, com a presença de professores Surdos, instrutores e intérpretes de libras, em que seja possível construir um espaço de socialização e aprendizagem da Língua de Sinais. Sem essa direção, possivelmente, o trajeto para se chegar à universidade será repleto de obstáculos.

É inegável, que os estudantes de Cultura Surda, em sua maioria jovens e usuários da Língua de Sinais, têm a possibilidade de construir variados projetos de vida, assim como as pessoas ouvintes almejam na vida adulta sua estabilidade financeira e familiar. Nessa transição entre juventude e idade adulta, a universidade é uma das possibilidades para se alcançar as projeções para o mercado de trabalho, carreira acadêmica e sua realização pessoal.

Quando nos referimos à projeto de vida, o fazemos a partir da definição apresentada por Nascimento (2006, p. 2), quando afirma ser aquele que está relacionado ao sentido de "aspirações, desejos de realizações, que se projetam para o futuro como uma visão antecipatória de acontecimentos [...] construída na interseção das relações que o sujeito estabelece com o mundo".

São poucos os estudos que tratam da temática projeto de vida de Surdos e sua trajetória de escolarização. As pesquisas de Gonçalves, Lobato e Nascimento (2014) sobre a "escolha profissional com jovens Surdos da região Marajoara" revela que a maioria desse grupo faz opção em escolher profissões ligadas à sua cultura linguística, a Libras, tais como: ser professor de Libras, instrutor de Surdos, e passar na proficiência da Língua Brasileira de Sinais (PROLIBRAS), ao concluir o ensino médio.

O estudo revela que o espaço no mercado de trabalho, infelizmente, ainda é limitado para o sujeito Surdo, o qual delimita também a definição de suas escolhas profissionais futuras. Muitas delas ancoram representações relacionadas à dimensão cultural ou linguística dos sujeitos Surdos, com o uso da Libras, o que faria com que ele tivesse mais oportunidade de alcançar seus objetivos profissionais. Contudo, o resultado não se detalha como regra, uma vez que muitos municípios já abrem espaços e apresentam outras oportunidades de mercado de trabalho, às quais o sujeito Surdo pode também concorrer.

Outra pesquisa que destaca a escolarização de surdos voltada para o ensino superior é de Valentini e Bisol (2012) que tratam sobre a "Inclusão no Ensino Superior: especificidades da prática docente com estudantes Surdos”. As autoras apontam que o espaço universitário é desafiador para a maioria dos Surdos que estão na fase da juventude, pois a adaptação à vida, nesse contexto, os leva a variadas obrigações acadêmicas, que, em alguns casos, se desdobram no insucesso e consequente abandono. Dessa forma, os Surdos precisam lidar "com as consequências de uma trajetória escolar anterior nem sempre satisfatória" (VALENTINI; BISOL, 2012, p. 49).

A escassez nesse debate, na universidade, reforça também dar atenção ao principal interlocutor que elabora Representações Sociais acerca de suas próprias vivências de escolarização - o aluno Surdo. Nesse sentido, é importante conhecer os projetos de vida dos Surdos universitários, principalmente dos jovens estudantes, pois significa dialogar com os 
múltiplos processos de representação/marginalização que a eles são impostos a partir da entrada em outro nível de ensino, sem esquecer, de sua trajetória de escolarização que é fundamental ou implicador nesse projeto. Afinal, como argumenta Scalon (2011), a polêmica sobre o enfrentamento das desigualdades está relacionada aos projetos de vida e ao que as políticas de "inclusão" e acessibilidade oferecem.

Nessa via, questionamos: quais os fatores que se relacionam para se chegar nos projetos de vida de estudantes Surdos por meio das representações sociais, advindas da trajetória escolar? E como questões norteadoras: Quais as contribuições da trajetória escolar de estudantes Surdos para a escolha de um projeto de vida?"; e, 2) “Quais habilidades são desenvolvidas ao longo da escolarização para construir o projeto de vida de estudantes Surdos?

\section{Metodologia}

Para chegarmos à determinação da relação entre os processos de escolarização e os efeitos nos projetos de vida de estudantes Surdos foi necessário fazermos o uso da técnica de associação livre de palavras (TALP) e do questionário semiaberto. A TALP é:

Um instrumento que se estrutura sobre um repertório conceitual vinculado a um tipo de investigação aberta, que possibilita colocar em evidência os universos semânticos constituídos face aos diferentes estímulos ou palavras indutoras e aos diferentes grupos [...] (NOBREGA; COUTINHO, 2003, p. 68).

O questionário semiaberto é aquele que consiste em um conjunto de questões préelaboradas, sistemáticas e sequencialmente dispostas em itens que constituem o tema da pesquisa (CHIZZOTTI, 2006). A ligação dos dados da TALP foi necessária para comparar ou acrescentar com os dados reveladores do questionário semiaberto. Feito isso, foi possível chegar a correlação e ao mesmo tempo conseguir apreender os processos implicadores de um sobre o outro no conjunto das Representações Sociais (RS) dos sujeitos.

A pesquisa foi realizada por meio de filmagens e com o apoio de tradutores e intérpretes de Libras (TILS). A coleta se deu de forma individualizada, nos municípios onde cada Surdo residia. A coleta ocorreu no período de um ano, considerando os contatos iniciais, a assinatura do Termo de consentimento livre e esclarecido da pesquisa, a aplicação dos instrumentos; o processo de tradução e o retorno ao participante das informações traduzidas. Em alguns casos, foi necessário o retorno no município para entrevistas complementares.

Os dados foram tratados a partir da associação entre fatores que se relacionam para se chegar as RS. Esse processo proporciona criar uma árvore cognitiva acerca do cruzamento das palavras-chave com o objeto em questão em forma de diagrama. Essa análise não tem caráter quantitativo, pois a preocupação está nas revelações das evocações, resultantes dos conteúdos dos sujeitos que se articulam para a definição de implicadores de Representações (GONÇALVES, 2016).

O objetivo dessa análise foi efetuar agrupamentos a partir de núcleos que se agregam com base em características e evocações pertinentes dos participantes. Nesse sentido, a 
correlação dessa associação de fatores permite obter proximidades entre formas lexicais, tipos de opiniões e depois interpretá-las. A construção dessa árvore foi possível com a utilização do Programa computacional Edraw mind map, criado pela empresa Edrawsoft iii $^{\text {. Este }}$ programa permite organizar a síntese das evocações, que tem como opção "deixar o pesquisador organizar ou criar um modelo que se adeque as suas necessidades visuais e de análise por meio de mapas mentais" (HERMANN; BOVO, 2005).

Esses programas permitem estabelecer com mais precisão e rapidez a imagem que relaciona as palavras com os pontos que produzem os efeitos da representação. $\mathrm{Na}$ continuidade, foi necessário descrever analiticamente a sequência das associações e cruzamentos que estruturam as RS e seus impactos no projeto de vida dos Surdos.

Participaram da pesquisa cinco estudantes Surdos universitários matriculados em cursos de graduação da Universidade Federal do Pará (UFPA) e Universidade Federal do Oeste do Pará (UFOPA), de 19 a 29 anos de idade, usuários da Língua Brasileira de Sinais. Esses sujeitos se identificaram na pesquisa pelos pseudônimos: Muiraquitã, Miriti, Tapajoara, Docinho e Manauara.

A escolha do lócus se deu com base em três critérios. Primeiro, por serem instituições que possuem um histórico de políticas voltadas para a inclusão. Segundo, por terem alunos Surdos matriculados em seus cursos de graduação, no período correspondente aos anos de 2011 a 2013. E, por último, por ofertarem vagas para Pessoa com Deficiência (PcD) nos seus processos seletivos. Nesse sentido, das quatro universidades federais no estado do Pará, foi possível identificar apenas em duas delas o conjunto desses critérios de seleção do lócus: a UFPA e UFOPA.

Vale destacarmos que o levantamento realizado nessas duas instituições possibilitou que atingíssemos o total de $100 \%$ dos sujeitos Surdos matriculados nessas universidades federais no período de 2011 a 2013, que totalizaram cinco alunos Surdos distribuídos no campus Belém - UFPA (01) e Abaetetuba - UFPA (01); e três na UFOPA, matriculados no campus de Santarém. Todos esses alunos em questão são usuários da Língua Brasileira de Sinais. O ingresso desses estudantes Surdos nessas instituições, se deu por meio da implementação de cotas para Pessoas com Deficiência ${ }^{\text {iv }}$ (cota PcD) e Mobilidade Externa $(\mathrm{MOBEX})^{\mathrm{v}}$ por meio da vaga de reserva PcD. A cota PcD se consolidou a partir do ano de 2011 na UFPA, aprovada pela Resolução CONSEPE No 3883/2009, e na UFOPA, no ano de 2012, por meio do Mobex com vagas específicas para PcD, e, em 2012 com a política de cotas PcD nos processos seletivos, consideradas como políticas de acesso e principal entrada dos alunos Surdos.

Os cursos que estavam matriculados no período de 2011-2013 eram: Licenciatura em Letras Libras/Língua Portuguesa como segunda Língua para Surdos e o curso de Licenciatura em Pedagogia. 


\section{A teoria das representações sociais}

A Teoria das Representações Sociais (TRS), escolhida como aporte teórico e metodológico de base deste estudo, foi iniciada em 1961, cujo mentor é Serge Moscovici. Esta teoria foi difundida por outros pesquisadores como Jodelet (2001), Abric (1998), Doise (1995), Marková (2006) e outros que criaram vertentes dentro da teoria maior. Essas teorias são denominadas de processual, estrutural, societal e dialógica, que a cada ano se fortalecem na busca da compreensão de determinados objetos, de ordem psicossocial, relacionadas à economia, educação, saúde e outros.

Como o estudo aqui proposto está vinculado à apreensão do processo de escolarização e os impactos nos projetos de vida dos Surdos universitários a eles relacionados, priorizou-se dentre as abordagens, a denominada processual ou dinâmica no campo educacional. As pesquisas em educação a partir da abordagem psicossocial das RS têm como intenção compreender os processos simbólicos que ocorrem na interação educativa, pois essas não ocorrem num vazio social (ALVES-MAZZOTTI, 2008).

A teoria das Representações Sociais na abordagem processual é importante neste estudo, pois nos permite visualizar a partir dos processos formativos a passagem de conceitos para esquemas ou ideias concretas, assim como o processo que constitui rede de significados em torno de determinado objeto, podendo relacionar à valores e práticas sociais (MOSCOVICI, 2012) que são objetivadas e ancoradas na base de conhecimentos socialmente construídos.

Jodelet (2001), por sua vez, afirma que o estudo das Representações Sociais constitui uma contribuição importante para a "abordagem da vida mental, individual e coletiva [...] são abordadas concomitantemente como produto e processo de uma atividade de apropriação da realidade exterior ao pensamento e de elaboração psicológica e social dessa realidade" (JODELET, 2001, p. 22, grifo nosso).

Spink (1995) também aponta que as Representações Sociais orientam as ações dos indivíduos a partir de suas condutas e diálogos, o que significa afirmar que são formas de conhecimento prático existente no cotidiano. Por ser prático, é construído por meio de interações sociais, com vistas à compreensão e ação sobre a realidade social que cada pessoa vive ou conviveu.

Nesse sentido, uma Representação Social que construímos a respeito de um determinado objeto não-familiar é um esforço constante de "tornar comum e real algo que é incomum" (MOSCOVICI, 2011, p. 58). Esse esforço é necessário para trazer o objeto estranho a um contexto que faça parte do universo consensual de cada indivíduo.

Para esclarecer melhor esse conceito de familiaridade, Moscovici (2011, p. 54), exemplifica:

O que eu quero dizer é que os universos consensuais são locais onde todos querem sentir-se em casa, a salvo de qualquer risco, atrito ou conflito. Tudo o que é dito ou feito ali, apenas confirma as crenças e as interpretações adquiridas, corrobora, mais do que contradiz a tradição. Espera-se que sempre aconteçam, sempre de novo, as 
mesmas situações, gestos, ideias. A mudança como tal somente é percebida e aceita desde que ela apresente um tipo de vivência e evite o murchar do diálogo, sob o peso da repetição. Em seu todo, a dinâmica das reações é uma dinâmica de familiarização.

É por meio desse processo constante na busca da familiaridade que o indivíduo pode superar o que lhe é incomum. O objeto nesse sentido, passa a fazer parte do conjunto de imagens e sentidos presentes em nossas mentes. Assim, o que antes era abstrato (nãofamiliar) passa a se tornar concreto (familiar), o que fortalece o sentimento de continuidade em um determinado grupo. Nesse caso, o exercício constante é transformar o não-familiar em algo familiar.

Depois de uma série de esforços e ajustamentos, o que estava longe para o sujeito parece ao alcance de sua mão, quase concreto, normal (familiar), e ao longo desse esforço é percebido que as imagens e ideias com as quais é compreendido o incomum apenas nos trazem de volta ao que já é conhecido por nós, com nossa familiaridade, ou seja, com "algo já visto (déja visto) e já conhecido (déjà connu)" (MOSCOVICI, 2011, p. 59).

\section{Os elementos da trajetória escolar e as implicações nos projetos de vida de estudantes surdos}

Com o uso do programa computacional Edraw mind map, criado pela empresa edrawsoft (2004), foi possível construir as amarrações das representações sociais que cruzavam as implicações dos projetos de vida dos estudantes Surdos, com as suas memórias vivenciadas e apreendidas nos processos, que construíram a sua história de escolarização desde a Educação Infantil até o Ensino Superior.

A partir da imagem que construímos resultante dos recortes e da TALP foi possível percebermos que os projetos de vida dos estudantes Surdos se estruturam a partir da construção histórica de suas vivências no âmbito escolar, principalmente às relacionadas na educação básica. $\mathrm{O}$ desencadeamento das influências decorrentes dessa vivência no processo escolar ajudou os alunos Surdos em três elementos: ter conhecimento; se desenvolver e descobrir seus interesses; enfrentar desafios. Esses elementos implicaram em escolhas futuras: ser profissional da área da surdez e continuar estudando. 
Figura 1. Análise da correlação processos de escolarização e os impactos nos projetos de vida de Surdos universitários

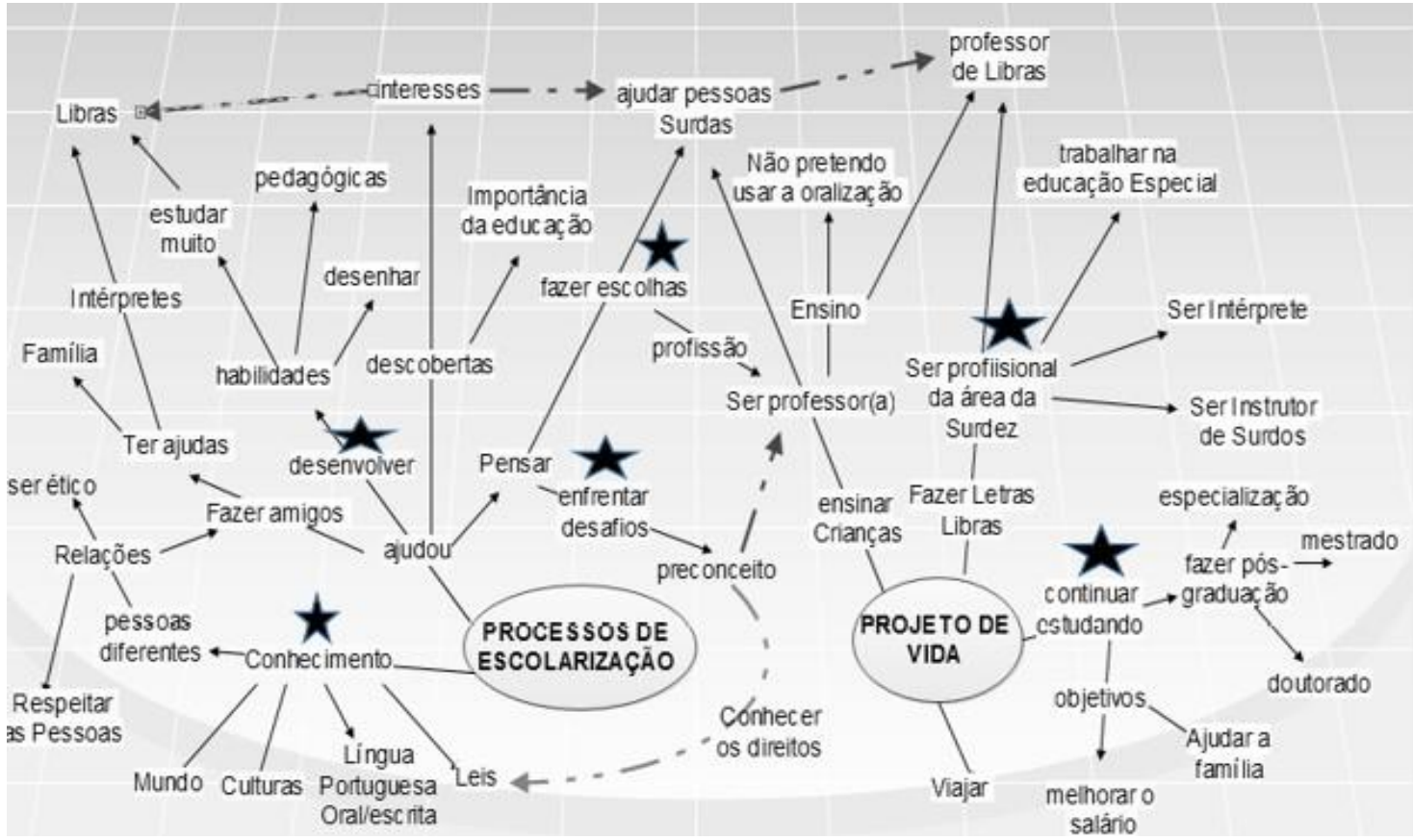

Fonte: Gonçalves (2016). Banco de dados da pesquisa, Programa Edraw Mind Map (2015).

\section{Elementos da trajetória escolar: conhecimento, habilidades e desafios}

\section{Conhecimento}

Foi na escola que eles adquiriram o conhecimento das Leis, da Língua Portuguesa escrita e oral, as variadas culturas e o mundo por meio dos livros e das disciplinas. Segundo Miriti, a escola foi um espaço para que ele pudesse:

Conhecer a importância da educação na vida das pessoas especiais. Conhecer o mundo com uma visão diferente, pessoas e culturas diferentes e também a relação com as pessoas. Vi que é necessário conhecer os nossos direitos, as leis e estudar. (MIRITI, sujeito da pesquisa, tradução Arlete Marinho Gonçalves).

Uma outra forma de conhecimento se deu a partir das relações que eles construíram no ambiente escolar. Foi por meio desses contatos que eles perceberam que as pessoas são diferentes e assim, aprenderam a respeitá-las e ser ético.

Fazer ou construir amizades, mesmo com poucos, foi importante para obterem as ajudas necessárias na sala de aula. No que diz respeito às ajudas os estudantes Surdos também obtiveram em seu processo de escolarização a ajuda da família e dos intérpretes no ensino médio e na Universidade.

Fernandes e Correia (2010) ressaltam que é importante a pessoa Surda obter o conhecimento da Língua de Sinais, como nova ou mais uma possibilidade de comunicação, 
por considerar ideal para continuar se desenvolvendo social e cognitivamente, assim como, ter à sua disposição os caminhos naturais de seu desenvolvimento.

Há uma série de mudanças de sentidos e sentimentos, que com a ajuda da família pode ser amenizada se a mesma propiciar para a pessoa Surda, a exposição a uma Língua o mais cedo possível, para que assim, possa garantir a tempo, a continuidade de seu desenvolvimento cognitivo, emocional e cultural.

Esses contatos foram fundamentais para que eles pudessem também aprender e valorizar a Libras.

\section{Habilidades}

Segundo Manauara, um dos sujeitos da pesquisa, a Escola o ajudou no desenvolvimento de seus estudos. Ele afirma: "A escola me desenvolveu nos estudos. No passado eu não sabia Libras, agora percebo que preciso estudar muito para ajudar outras pessoas Surdas a chegarem na faculdade, sabendo Libras".

$\mathrm{Na}$ escola aprenderam a se desenvolver e ganhar variadas habilidades, como estudar muito, desenhar e obter habilidades pedagógicas. Essas habilidades se deram a partir dos incansáveis treinos de memorização com a ajuda da família e dos amigos para conseguirem obter aprovações nas disciplinas e também como forma de superar as suas dificuldades.

Nesse sentido, os estudantes Surdos criavam para atender as suas necessidades, variadas estratégias de aprendizagem para acompanhar a turma, uma vez que, nos anos (séries) iniciais e finais, a maioria deles não contavam com instrutores, professores ou intérpretes de Libras para ajudar na acessibilidade de comunicação.

\section{Enfrentar desafios}

As vivências no espaço escolar fizeram também os Surdos descobrirem a importância da educação e também os seus interesses, uma delas foi a descoberta da necessidade de aprender a Língua Brasileira de Sinais.

Esse processo de escolarização dos Surdos ajudou cada um deles a pensar no enfrentamento dos desafios e em fazer escolhas futuras. No que diz respeito ao enfrentamento dos desafios, uma das marcas, muito repetitiva neste estudo, foram as marcas do preconceito que ocorreram em quase todas as etapas da escolarização dos Surdos. Essa situação levou muitos deles, a partir dos conhecimentos recebidos pela Escola a conhecer os seus direitos e reivindicar por eles.

A marca depreciativa, caracterizada por estigmas, discriminação e preconceito para com as pessoas Surdas é vista por Botelho (2010) como um sentimento produzido pelo outro de incapacidade, que implica na relutância da aceitação de "limites e erros", depreciação do desempenho e a preocupação com a aprovação ou não nas disciplinas escolares. Essa 
combinação de sentimentos, vividas pelos alunos Surdos, os leva a outra forma de segregação - o isolamento na sala de aula.

\section{Projeto de vida: Ser professor e continuar estudando}

\section{Ser profissional da área da Surdez.}

O preconceito, fez com que os estudantes Surdos pudessem refletir acerca de um dos seus projetos de vida, ou seja, os ajudou a pensarem nas suas escolhas futuras. Uma delas, muito presente nos discursos dos Sujeitos foi a de ajudar pessoas Surdas como profissionais da área. Sendo assim, uma das opções marcantes como escolha de projeto de vida profissional foi a de ser professor.

Nessa direção, Goldfeld (2002) defende a ideia de que todos podem estudar e agir a favor da comunidade de Surdos, de sua língua e de sua cultura própria, no sentido de estimular e divulgar a Língua brasileira de sinais

O discurso de Miriti retrata isso, quando afirma: "Estou feliz e alegre com minha formação na faculdade, pois depois vou poder ajudar a sociedade, pessoas surdas e especiais, e no futuro quero ser professor de Libras" (MIRITI). Muiraquitã também reforça essa escolha quando diz: "Não tive muita ajuda dos meus professores na minha escolarização. Hoje eu penso em ser professor para ajudar outros surdos e dar aula de Libras na Educação Especial" (MUIRAQUITÃ).

Com essa opção, percebemos que a escolha pela maioria dos Surdos em tornar-se professor futuramente e de preferência da disciplina Libras está carregada de representações relacionadas ao seu processo de escolarização, envolvido por falta de acessibilidade de comunicação e também pelo preconceito. Este último esteve relacionado ao fato da maioria dos ouvintes e do próprio Surdo não conhecer a Libras como meio de comunicação e interação surdo-ouvinte.

Nessa direção, ser professor para cada um não é um projeto de vida apenas como escolha profissional, mas também como uma opção de alteridade e de respeito à comunidade e cultura Surda. Assim, alguns Surdos ressaltam que a sua forma de ensinar não seria baseada no oralismo, porque esse método é carregado de representações negativas vivenciadas por eles no passado, em especial, no Nível I de escolarização. Nessa via, um dos sujeitos da pesquisa relata:

\footnotetext{
Não pretendo usar a oralidade para ajudar outros surdos na descoberta de seus caminhos, uma vez que estes possuem a Libras para seu auxílio de comunicação, enquanto eu, por não conhecer a Língua de Sinais na infância, fui impossibilitada de usá-la como recurso, mas usar o Português L2 como forma de aprendizado para o crescimento escolar dos mesmos será importante. Desenvolvi a Libras nos últimos anos na escola e faculdade de Letras Libras/LP2 (DOCINHO, tradução Arlete Marinho Gonçalves).
} 
Diante do exposto, esse processo de ensino, como um projeto de vida, seria trabalhar com Surdos a partir da sua língua primeira - a Língua de Sinais, sem perder o foco também na importância da aprendizagem da Língua portuguesa escrita. Sendo assim, a proposta de Docinho seria ser professora de Libras a partir do uso do método bilíngue para Surdos e ouvintes. O fato de Docinho fazer o curso de Letras Libras, nos faz perceber que nas suas representações Sociais, a mesma tem a preocupação do Surdo aprender as duas Línguas, contudo daria maior ênfase, inicialmente para a Libras, como primeira Língua.

Nesse caminho é visível, a partir da árvore cognitiva dessas correlações que o processo vivenciado pelos Surdos na escolarização os ajudou a descobrir habilidades e aprender a importância da Libras para o seu desenvolvimento, e para ajudar outros Surdos, principalmente as crianças. Essa ajuda é marcada com a escolha de ser profissional da área da educação de Surdos, podendo ser professor de Libras, trabalhar na educação especial, ser intérprete ${ }^{\mathrm{vi}}$, vejamos:

Poderei ser profissional da área da surdez, atuando como Intérprete, professor ou Instrutor de surdos (MANAUARA e MIRITI, tradução Arlete Marinho Gonçalves).

A minha formação na Universidade poderá me possibilitar ajudar outros surdos em trabalhos comunitários, melhorar meu salário e as condições de minha família e ser um bom profissional na área da Surdez (MUIRAQUIT ̃̃, tradução Arlete Marinho Gonçalves).

Outro caminho que ajudou os Universitários a optar pela docência foi a própria escolha pelo curso de pedagogia ou pela licenciatura de Letras Libras/LP2. De acordo com Tapajoara (sujeito da pesquisa), ela queria quando criança trabalhar na área da saúde, mas não conseguiu ingressar no curso, devido as barreiras impostas pelo processo seletivo ofertado por meio do Exame Nacional do Ensino Médio (ENEM) e também pela alta concorrência. Decidiu então, pelo curso de pedagogia devido à concorrência ser menor. Ao ingressar nesse curso, a aluna percebeu, no decorrer das disciplinas, que essa profissão poderia lhe ajudar a definir o seu projeto de vida, e assim o fez, pois, o curso lhe proporcionou a gostar e se identificar com a profissão docente. Ela afirma: "No passado, eu queria ser enfermeira, pensava muito nessa profissão. Agora no curso de pedagogia, me ajudou a pensar num futuro em ser professora, ensinar para crianças” (TAPAJOARA).

\section{Continuar estudando}

Outro projeto de vida marcado nas falas dos universitários Surdos foi o desejo de continuar estudando. O objetivo de continuar os estudos após o término da graduação foi sinalado pelo desejo de fazer a pós-graduação, tais como a especialização, mestrados ou doutorados para que possam futuramente melhorar os seus salários como docentes, ajudar as suas famílias e contribuir para a melhoria da educação de Surdos. Esses relatos se encontram presentes nos discursos de Tapajoara, Muiraquitã e Docinho, quando dizem: 
Contribuirá para continuar meus estudos e conseguir futuramente uma especialização, mestrado ou doutorado (TAPAJOARA, tradução Arlete Marinho Gonçalves).

Proporciona a Escolha de uma profissão; Contribuirá para continuar meus estudos e conseguir futuramente uma especialização, mestrado ou doutorado (MUIRAQUITÃ, tradução Arlete Marinho Gonçalves)

Contribuirá para continuar meus estudos e conseguir futuramente uma especialização, mestrado ou doutorado; e ser um bom profissional na área da Surdez (DOCINHO, tradução Arlete Marinho Gonçalves).

Os elementos apreendidos nas RS: Ter conhecimento; Se desenvolver e descobrir seus interesses; e, Enfrentar desafios influenciaram diretamente e indiretamente a construção dos projetos de vida desses estudantes Surdos que se voltaram para escolhas como continuar estudando e ser profissional na área da surdez. Contudo, como eles ressaltam, o projeto de ser professor é apenas o começo para ajudar outros Surdos, pois em sua maioria, sonham em continuar estudando e se aperfeiçoando, no sentido de ganhar mais qualificação na área da educação de Surdos.

Dentre os aspectos que se encontram intrínsecos estão: a relação subjetiva de se colocar no lugar do outro (de seus pares), de pensar na melhoria da educação para os alunos de Cultura Surda, isto é, dos alunos usuários da Língua brasileira de sinais desde a sua primeira infância. São relatos fortes, marcantes, que nos fazem, enquanto ouvintes, também fazermos uma reflexão em cima de nossas práticas pedagógicas, como professores de Libras para com as pessoas Surdas e a formação desses futuros profissionais da educação.

\section{Considerações finais}

A relação existente entre os processos de escolarização com os projetos de vida dos sujeitos Surdos universitários nos levaram a construir uma árvore cognitiva ou dos sentidos com palavras-chave que desenrolaram e ao mesmo tempo proporcionaram as amarrações do objeto social. Nela, foi possível percebermos que os projetos de vida dos universitários Surdos se estruturam a partir da construção histórica das vivências dos sujeitos no âmbito escolar, principalmente àquelas ocorridas na educação básica.

O desencadeamento dessas influências decorrentes dessa vivência no processo escolar ajudou os sujeitos Surdos a se relacionarem com outras pessoas, fazer descobertas e pensar em escolhas futuras. A escola também proporcionou a abertura de novos horizontes, culturas, e novos conhecimentos, descobertos pelas palavras e imagens presentes nos livros de cada disciplina do currículo.

Foi na construção das relações sociais experienciadas na escola que fizeram os estudantes Surdos a obterem as ajudas necessárias na sala de aula. Esses contatos foram fundamentais para que os seus colegas também pudessem aprender e valorizar a Libras. A escola foi um lugar "recheado" de descobertas. Foi nela, também, que aprenderam a se desenvolver e ganhar variadas habilidades, como estudar muito, desenhar e ter habilidades pedagógicas. 
Essas habilidades se concretizaram pelo esforço individual de cada um, mas também, pelos incansáveis treinos de memorização que foram necessários para alcançar suas metas e objetivos em cada matriz curricular. No que diz respeito ao enfrentamento dos desafios, uma das marcas, foi o preconceito, já citado anteriormente e sentido "na pele" por eles. Esse preconceito ocorreu em todas as etapas da escolarização dos Surdos. Essa situação, por outro lado, propiciou, a cada um, conhecer os seus direitos e lutar por eles.

A palavra preconceito foi tão marcante que fez com que os Sujeitos Surdos pudessem refletir acerca de um dos projetos de vida: ajudar pessoas Surdas como futuros profissionais da área, tornando-se professor na Educação Básica ou como professor de Libras no Ensino Superior. A construção dessa ideia se concentra em representações de alteridade, ou seja, de poder fazer a diferença na vida das pessoas Surdas.

Nessa direção, ser professor para o sujeito Surdo não se limita apenas a um projeto de vida decorrente de uma escolha profissional, mas está envolvido com a opção de alteridade e de respeito à comunidade de cultura Surda. Outro caminho que ajudou os Universitários a optarem pela docência foi a própria escolha pelo curso de pedagogia ou pela licenciatura de Letras Libras/LP2 que fortalece a compreensão da profissão docente. O projeto de vida dos sujeitos Surdos não se limita apenas em ser professor. Alguns deles têm o desejo de continuar estudando e se aprimorando, tal como, fazer a pós-graduação lato e stricto sensu (mestrados e doutorados).

Em resumo, as correlações que assinalam o processo de escolarização com os projetos de vida dos estudantes Surdos foram apontadas pelas situações de exclusão vivenciadas na educação básica, a descoberta da Língua de Sinais como uma das melhores opções para o seu desenvolvimento escolar e a escolha da faculdade, as quais adentraram como alternativa de curso.

Esses três aspectos influenciaram diretamente e indiretamente a construção dos projetos de vida desses sujeitos. Ressaltamos que o projeto de ser professor não é o fim em si mesmo, pois sonham com a continuidade de seus estudos e no aprimoramento na área da educação de Surdos e ao respeito à Libras.

Esse reconhecimento não é apenas da língua, mas também, de como cada um aprende e apreende o mundo. Entender isso, já é um grande passo para pensarmos estratégias diferenciadas e acessíveis a esse público, que a cada ano, vem ingressando nos espaços de educação superior.

\section{Referências}

ABRIC, Jean Claude. Abordagem estrutural das representações sociais. In. MOREIRA, Antonia Silva Paredes; OLIVEIRA, Denize Cristina de (org.). Estudos Interdisciplinares de Representação Social. Goiânia, Go: AB Editora, 1998. p. 27-38.

ALVES-MAZZOTTI, Alda Judith. Representações Sociais: aspectos teóricos e aplicações à educação. Revista múltiplas leituras, v.1, n. 1, p. 18-43, jan./jun. 2008. 
BOTELHO, Paula. Linguagem e letramento na educação dos Surdos: ideologias e práticas pedagógicas. 3 ed. Belo Horizonte: Autêntica Editora, 2010.

BRASIL. Decreto n. 5.626, de 22 de dezembro de 2005. Regulamente a Lei n. 10.436, de 24 de abril de 2002, que dispõe sobre a Língua Brasileira de Sinais - Libras, e o art. 18 da Lei n. 10.092, de 19 de dezembro de 2000. Brasília, DF: Presidência da República, 2005.

BRASIL. Censo Demográfico 2010. Instituto Brasileiro de Geografia e Estatística (IBGE), 2010. Disponível em: https://ww2.ibge.gov.br/home/estatistica/populacao/censo2010/default.shtm. Acesso em: 20 set. 2016.

CHIZZOTTI, Antonio. Pesquisa em Ciências Humanas e Sociais. 8. ed. São Paulo: Cortez, 2006.

DAMÁZIO, Mirlene Ferreira Macedo. Atendimento Educacional Especializado: Pessoa com Surdez. Brasília/DF: SEESP/SEED/MEC, 2007.

DOISE, Willem. Representations et relations entre groupes. In.: MOSCOVICI, Serge.

Introctucion à la Psychologie Sociale. Paris: Larousse, 1995.

EDRAW MIND MAP. Programa computacional. Hong Kong, 2004. Disponível em: www.edrawsoft.com. Acesso: 10 jan. 2013.

FERNANDES, Eulália; CORREIA, Claudio Manoel de Carvalho. Bilinguismo e Surdez: A evolução dos conceitos no domínio da Linguagem. In.: FERNANDES, Eulália (org.). Surdez e bilinguismo. Porto Alegre: Mediação, 2010. p. 7-25.

GOLDFELD, Marcia. A criança surda: linguagem e cognição numa perspectiva sóciointeracionista. 5. ed. São Paulo: Plexus Editora, 2002.

GONÇALVES, Arlete Marinho. Sinais de escolarização e as repercussões nos projetos de vida: Representações Sociais de universitários Surdos. 2016. 253 f. Tese (Doutorado em Educação) - Programa de Pós-graduação em Educação, Universidade Federal do Pará, Belém-PA, 2016.

GONÇALVES, Arlete Marinho; LOBATO, Huber Kliner Guedes; NASCIMENTO, Ivany Pinto. Quero ser professor de libras e ajudar os surdos": Representações Sociais de jovens surdos. Anais do VI Congresso Brasileiro de Educação Especial, UFSCAR, 2014. Disponível em: https://proceedings.science/cbee6/trabalhos\#q=arlete $\& p=0$. Acesso em: 20 set. 2016.

HERMANN, Walther; BOVO, Viviani. Mapas mentais: enriquecendo inteligências. São Paulo: IDPH, 2005.

JODELET, Denise. Representação Sociais: um domínio em expansão. In: JODELET, Denise. As Representações Sociais. Tradução Lilian Ulup. Rio de Janeiro: EDUERJ, 2001. p. $17-44$. 
MARKOVÁ, Ivana. Dialogicidade e Representações Sociais: as dinâmicas da mente. Petrópolis, RJ: Vozes, 2006.

MOSCOVICI, Serge. Representações Sociais. Investigações em psicologia social. 8 ed. Petrópolis: Vozes, 2011.

MOSCOVICI, Serge. A psicanálise, sua imagem e seu público. 2 ed. Petrópolis, RJ: Vozes, 2012.

NASCIMENTO, Ivany Pinto. Projeto de vida de adolescentes do ensino médio: um estudo psicossocial sobre suas representações. Imaginário, São Paulo, v. 12, n. 12, jun. 2006. Disponível em: http://pepsic.bvsalud.org/scielo.php?script=sci_arttext\&pid=S1413666X2006000100004. Acesso em: 08 set. 2012.

NÓBREGA, Sheva Maia da; COUTINHO, Maria da Penha de Lima. O teste de associação livre de palavras. In.: COUTINHO, Maria da Penha de Lima et al (org.). Representações sociais: Abordagem interdisciplinar. João pessoa: UFPB, 2003. p. 67-77.

SCALON, Celi. Desigualdade, pobreza e políticas públicas: Notas para um debate.

Contemporânea, n. 1 p. 49-68, jan./jun. 2011.

SPINK, Maria Jane Paris. Desvendando as Teorias Implícitas: uma Metodologia de Análise das Representações Sociais. In: GUARESCHI, Pedrinho; JOVCHELOVITCH, Sandra (org.). Textos em Representações Sociais. 4. ed. Petrópolis, RJ: Vozes, 1995. p. 117-148.

VALENTINI, Carla Beatris; BISOL, Claudia Alquati. Inclusão no ensino Superior: especificidades da prática docente com estudantes surdos. Caxias do Sul. RS: EDUCS, 2012.

\section{Notas}

${ }^{\text {i }}$ O Decreto 5626/2005 considera deficiência auditiva a perda bilateral, parcial ou total, de quarenta e um decibéis $(\mathrm{dB})$ ou mais, aferida por audiograma nas frequências de $500 \mathrm{~Hz}, 1.000 \mathrm{~Hz}, 2.000 \mathrm{~Hz}$ e $3.000 \mathrm{~Hz}$ (BRASIL, 2005).

ii Esse posicionamento é reflexo da minha atuação direta no Núcleo de Inclusão Social da Universidade Federal do Pará, junto a Pró-Reitoria de ensino de graduação, onde uma de minhas ações é acompanhar pedagogicamente alunos com deficiência auditiva ou Surdez durante o percurso da sua graduação. Uma das ações é ofertar o serviço de intérpretes de Libras, orientar os professores na avaliação do aluno, considerando sua singularidade linguística e acompanhar o rendimento escolar durante o percurso do curso escolhido.

iii EdrawSoft é um provedor líder de aplicações baseadas em desenho. Fundada formalmente em abril de 2004 com um pequeno escritório especializado em desenvolvimento de diagramas de software, desenvolvimento de componentes gráficos e aplicações baseadas na web. A empresa desde então tem sido promovida por profissionais altamente experientes dedicados a fornecer uma solução completa de software de desenho em um único pacote.

${ }^{\text {iv }}$ Ressaltamos que nas universidades federais no Estado no Pará ainda não há processo seletivo diferenciado para surdos. Nesse sentido, os surdos concorrem às vagas para Pessoas com Deficiência. Apesar da comunidade Surda, usuária da Língua de Sinais, não se enquadrar a esse estereótipo.

${ }^{v}$ Ingresso a partir da cota PcD na Mobilidade Externa.

${ }^{\mathrm{vi}}$ Ser Intérprete, nesse caso, seria para garantir a tradução e interpretação de uma Língua de Sinais para outra de países diferentes. Assim, seria uma Interpretação de Surdo para Surdo de Línguas de Sinais diferentes.

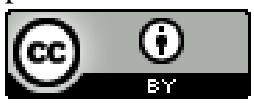

